\title{
Classificação de Cargos: Instrumento de Racionalização e Humanização do Trabalho
}

\author{
ENNOR DE ALMEIDA CARNEIRO \\ Professor Titular de Administração de Pessoal \\ da Faculdade de Ciências Administrativas \\ da SUAM - Guanabara
}

\begin{abstract}
“... dignificar o exercício da função pública, delinear em têrmos precisos a idéia de profissionalização do servidor e prover a Administração de pessoal realmente capacitado para o desempenho de suas tarefas" (E. M. $n$ ? 168, de 22-10-70, que encaminhou anteprojeto da Lei $n$ ? 5.645 , de 10-12-1970).
\end{abstract}

A Classificação dos Cargos do Serviço Público Civil é uma constante da problemática administrativa brasileira. Em tôdas as tentativas para racionalizar métodos de trabalho e aprimorar a prestação de serviços, desde os ensaios mais remotos até as inovações mais recentes - afluentes da reforma de grande envergadura consubstanciada no Decreto-lei n? 200/67 -, aflora, sempre, o tema da Classificação de Cargos. E é natural que assim seja porque os cargos são as verdadeiras células do organismo administrativo, que se estrutura e se desenvolve através dêles e em função dêles. As organizações valem pelos homens que as compõem. Repeti-lo pareceria uma verdade banal se Cabannes não nos tivesse, algures, prevenido de que o truismo é, às vêzes, apenas "o longo hábito de uma idéia falsa". O aforismo, neste caso, continuará verdadeiro, pelo menos até que a automação substitua o último bípede implume. Isto não obstante os avanços da tecnologia e a "glamurização" do computador - êsse Deus dos agnósticos - , porque a máquina pensante não existe e não será construída. Se fôsse construída, cairiamos num grotesco círculo vicioso, pois o homem se tornaria obsoleto e os andróides que o substituíssem não teriam sossêgo enquanto não inventassem, também, máquinas capazes de pensar por êle. Apesar dessa evidência, a excitação mecanicista já é sesquicentenária, já que os idólatras do instru- 
mento estão tentando fazer a máquina pensar desde 1820 , quando Babbage inventou um "calculador" portentoso que se encontra, hoje, no Museu de Ciências de Londres, definido com humor, por Magnus Pike, como "uma bela máquina, infalível mas inútil". De qualquer forma, é preciso ter paciência com os fabricantes de máquinas e os seus exageros inócuos, pois o único perigo verdadeiro é a subversão dos valôres, ou como se expressa o prof. Höffner: "a apostasia da ordem moral". Por enquanto, o computador mais sofisticado limita-se a cumprir, com exemplar disciplina, o vertiginoso papel de processar dados a velocidades insólitas.

A automação, por outro lado, apesar de prodigiosas façanhas, não alijou o homem nem sequer do trabalho manual. A divisão do trabalho far-se-á, ainda, entre os homens, e êsse panorama não tem aparência de modificações propínquas. Observou-o, recentemente, com muita propriedade, Elwood Bufa:

"In spite of the great advance in computer and automation technology, manual labor at various levels is predominant today. This situation will be in effect for a long time; therefore we should expect the design of jobs and of the methods used will continue to be emphasized in production management". 1

Esta breve divagação é para poder insistir no lugar-comum de que o fator essencial, fundamental, primeiro e último, causa, fim e instrumento de qualquer tentativa destinada a tornar produtivo o trabalho é o homem. O homem e aquilo que êle faz, como faz e por que faz. Em suma: o homem e o cargo. Assim será, pelo menos enquanto o homem puder ser definido como "aquêle que é capaz de tomar decisões", até mesmo a decisão de fabricar máquinas capazes de fabricar outras máquinas. Não há, por isso mesmo, nenhum meio de racionalizar os serviços civis - corrigir os seus vícios de concepção e deformações de funcionamento; converter organismos reconhecidamente obsoletos, parasitários ou estanques em entidades modernas, sadias e integradas sem o preliminar reconhecimento de que o homem, não obstante as suas notórias imperfeições, é o elemento essencial do sistema, o único imprescindivel, pois permeia tôda a estrutura, imprimindo-Ihe conteúdo, energia vital e significado. Compreendida a relevância do componente humano das organizações, só então será possivel retracejar os esquemas de comu-

1. Elwood Bufa - "Production Management", John Wiley \& Sons International Edition; NY, 1969. 
nicação e contrôle, redefinir competência e delegar autoridade, construindo sistemas inteiriços, assim entendidos os conjuntos cujas partes - embora autônomas, responsáveis, independentes - se engrenam sem fricção na marcha para um objetivo comum. Mas o fenômeno de formação do conjunto, a partir das partes que o compõem ou, vice-versa, da atomização do trabalho global em seus elementos constitutivos, tem de ser compreendido através da noção de que as organizações só atingem níveis desejáveis de estabilidade quando são hieràrquicamente ordenadas. Mas, por outro lado, é indispensável atentar para a relatividade das concepções de "parte" e "todo" como expressões de subconjunto e conjunto. Eis como a questão é focalizada pela atilada percepção de Arthur Koestler:

"Uma "parte", como geralmente usamos a palavra, significa algo fragmentário e incompleto, que não teria nenhuma existência por si mesma. Por outro lado, um "todo" é considerado algo completo em si mesmo, que dispensa qualquer explicação adicional. Mas "todos" e "partes", nesse sentido absoluto, simplesmente não existem em lugar nenhum, no domínio dos organismos vivos ou das organizações sociais. O que encontramos são estruturas intermediárias, em diversos niveis e numa ordem ascendente de complexidade: "subtodos" que revelam, de acôrdo com a maneira pela qual os observamos, algumas das características comumente atribuidas aos "todos" e algumas das características comumente atribuídas às partes." 2

Nessa ordem de idéias é que sobrelevam para o administrador os estudos de classificação de cargos, porque a consideração do homem no trabalho tem de abranger o duplo aspecto do indivíduo, em seus valôres universais, e do trabalhador ocupante de cargo, responsável pelo desempenho de tarefas específicas. Neste contexto, a organização do trabalho vê o homem refletido nas peculiaridades da função que exerce. $O$ tipo e a complexidade das tarefas; a aptidão, a instrução e a habilidade necessárias para executá-los; o grau e teor da responsabilidade que acompanha a incumbência, são todos elementos integrantes de um complexo - o cargo - que, por sua vez, é parte de um conjunto, êste também parte de outro, e êste de outro mais, em sucessivas ordens de grandeza. Tudo aquilo que se realiza dentro de uma organização, sejam quais forem os procedimentos tecnológicos e o instrumental utilizado, é pro-

2. Arthur Koestler: "O Fantasma da Máquina", Zahar Editôres Rio, 1969. 
duto do trabalho humano. Organizar serviços, em qualquer circunstância e para qualquer fim, é, em última instância, organizar o trabalho. E organizar o trabalho significa, nada mais, nada menos, concebê-lo e distribuí-lo. Conceber o trabalho é planejar - decidir o que terá de ser feito e como deverá ser feito. Distribuir o trabalho é dividi-lo em função dos recursos humanos disponíveis, consideradas as diferenças individuais. A conjugação dos requisitos das funções com as peculiaridades da individualidade humana é que irá configurar aquêle clássico "conjunto de deveres e responsabilidades cometiveis a uma pessoa" - unidade conceitual do trabalho organizado. Todavia, para que determinados deveres e responsabilidades possam constituir atribuição normal de um só indivíduo, é preciso haver um mínimo de congruência entre cada um dêsses deveres e as responsabilidades concomitantes. É a coesão dêsses componentes que dá ao cargo fisionomia unitária, embora êle seja apenas peça de um conjunto maior. O conjunto maior é o somatório dos cargos existentes; é a globalidade do trabalho realizado.

Com êstes pressupostos, é intuitivo que a entidade conceptual a que denominamos cargo - exprimido com êsse vocábulo um composto de "situações de trabalho" - só poderá ser identificada e objetivada se as múltiplas variáveis que integram a supradita situação de trabalho forem objeto de estudo completo, realizado com rigor metodológico.

Assim, a concepção que assemelha os cargos às células de um organismo pressupõe a necessidade de identificá-los com clareza, defini-los com precisão e marcar-lhes os contornos com nitidez, de modo a permitir uma visualização instantânea do seu conteúdo ocupacional.

Daí a preocupação de dispensar-Ihes tratamento taxionômico, descrevendo-os, comparando-os, classificando-os. Vê-se, portanto, que o processo classificatório não se resume no esfôrço burocrático aparente, pois envolve o conhecimento dos princípios que informam a pesquisa científica e pressupõe o domínio das técnicas de levantamento, análise e medição dos fenômenos observados. Eis por que, ao cogitar da reorganização dos serviços públicos, que, òbviamente, compreende a racionalização dos métodos de trabalho, é impossível abstrair a noção de classificação de cargos. Em outras palavras: se, por um lado, o cargo é a unidade fundamental do trabalho e, por outro lado, a reorganização dos serviços só pode ser compreendida como racionalização do trabalho, é manifestamente impos- 
sivel conceber uma reforma administrativa sem classificação de cargos. É, por conseguinte, um artifício de valor duvidoso separar em compartimentos estanques atividades que se entrelaçam e se complementam, como acontece com a classificação de cargos e os processos organizatórios. Houve já quem pretendesse vincular a metodologia de classificação de cargos exclusivamente às disciplinas especializadas de O\&M, cancelando-a do rol das atividades setoriais de administração de pessoal. Essa posição foi sustentada em brilhante monografia - na verdade um trabalhoso exercício de retórica, porque na prática da administração as coisas se passam de modo diferente. Está claro, entretanto, que quando é necessário reformar em profundidade, as técnicas de análise e classificação, que constituem ferramentas insubstituíveis de trabalho na área de administração de pessoal, passam a funcionar, também, como instrumental do organizador.

Essa é a situação do serviço público civil: quando a máquina administrativa apresenta o síndrome dos emperramentos continuados, vias de acesso obstruidas, desempenho inferior aos padrões e custo elevado, resta apenas o remédio, impiedoso, da cirurgia mutiladora. Nada poderá justificar a sobrevivência dessas entidades teratológicas que surgem para satisfazer interêsses pessoais momentâneos e depois se perpetuam pela inércia, contaminando as partes sadias do organismo. O fenômeno é, certamente, comum na patologia das instituições, mas nem por isso justifica tratamento menos severo. Conseqüentemente, novos órgãos ou novas relações entre os órgãos mantidos terão de ser estabelecidos a fim de dar continuidade ao trabalho. A nova estrutura, todavia, terá de ser moldada em bases realísticas, para que se não produzam os erros do passado condenado. Entrementes, é preciso que as reformulações sejam empreendidas com objetividade, isto é, sem esquecer que na área dos Serviços Públicos, mesmo quando prevaleçam os melhores critérios de organização, a diversificação de atividades resultante do desenvolvimento tecnológico provoca recrudescência das esquematizações administrativas, quiçá com exacerbação dos procedimentos burocráticos. Isto se explica porque o Estado tem obrigação de organizar os Serviços Públicos de modo a não deixar coisa alguma ao acaso, e a mínima satisfação dessa exigência impõe padronizações rígidas, quase sempre indesejáveis, mas raramente contornáveis. "Everywhere today the Government is a bureaucracy" - escreviam Mosher \& Kingsley. Com efeito, ninguém mais admite um Serviço Público organizado sem uma estrutura hierárquica definida, onde cada cargo tenha, pre- 
determinada, a sua exata inserção - "like a cog in a complex machine" - diriam os autores citados. Mas uma estrutura capaz de retratar com legitimidade as relações existentes só é possível através da análise em profundidade do trabalho que está sendo feito - de quem o faz, como, por que e em que circunstância - e da verificação, concomitante, à luz de nôvo planejamento do que deverá efetivamente fazer-se.

Tudo o que tiver de ser feito o será pelo homem ou sob sua supervisão, e é tão complexa a urdidura das relações humanas no trabalho que jamais poderá compreendê-la o administrador que não fôr também capaz de perceber a importância da Classificação de Cargos (usada a expressão na sua multifária conotação, abrangendo os seguintes procedimentos: levantamento de dados e caracterização da função, análise e descrição, comparações, grupamentos, especificação e avaliação). No Serviço Público Civil brasileiro essa compreensão nunca faltou. A preocupação de analisar o trabalho e classificar as funções, reunindo-as em grupamentos homogêneos, a fim de permitir a visualização dos tipos de atividades existentes e seus relacionamentos, já se delineava na Lei no 284, de 1936, e nas primeiras medidas adotadas pelo vetusto Conselho Federal do Serviço Público Civil, elo de transição da pré-história para a história da racionalização dos serviços públicos, cujo primeiro evento é, sem dúvida nenhuma, o Decreto-lei n? 579 , de 30 de julho de 1938, que criou o DASP. Por isso mesmo que a problemática da Classificação de Cargos já se evidenciava nos fastos mais primitivos da história da racionalização do Serviço Público, é de lamentar que só em 1954 tenha sido possivel concluir o primeiro estudo técnico de classificação de cargos. E mais ainda de lamentar porque, de 1938 a 1954, transcorreram 16 anos vãos, durante os quais poderia ter-se acumulado longa experiência, quem sabe?, capaz de estar produzindo, a esta altura, frutos opimos. Porque estávamos tão defasados em 1954, com relação às práticas de classificação correntes em outros países, e portanto desprovidos de qualquer experiência efetiva, o trabaIho realizado pela Comissão do Plano de Classificação de Cargos, apesar do seu indiscutível mérito, não alcançou os resultados a que se propunha. Para fazer-lhe justiça, ter-se-ia de lembrar, também, que lutou contra as resistências obstinadas de uma longa tradição obscurantista em matéria de serviço público. Sem entrar em pormenores, bastaria lembrar as emendas disparatadas que distorceram o malsinado projeto na tramitação por um Congresso despreparado para compreender a importância do trabalho e a extrema urgência de que se revestia a sua implantação. A trajetória morosa, incoerente e vacilante que 0 
projeto sofreu na Câmara dos Deputados acabou por imprimir-lhe uma marcha de Sísifo, recaindo o problema nas mãos do Executivo para reformulação. A segunda versão, datada de 1960 , foi calcada no trabalho anterior, de que assimilou alguma experiência e a prova sofrida dos percalços, beneficiando-se, até, com os saldos positivos do escarcéu de interêsses que em tôrno da versão original se avolumou. Isso sem mencionar o escarmento da longa e inane tramitação legislativa. A tentativa não foi, talvez por isso, inteiramente baldada, pois o nôvo projeto mereceu, afinal, o beneplácito legislativo, que o converteu na Lei $n$ ? 3.780, de 12 de julho de 1960. Mas êsse segundo projeto como o que o precedeu estavam ambos viciados pelo anacronismo: os seus parâmetros eram falsos, não tinham compatibilidade com a equação em que figuravam, pois queriam regular uma situação deteriorada, que não devia ser ratificada pelos registros da classificação, mas, pelo contrário, contestada e substituída. A prova do que afirmamos é que o Plano de Classificação de Cargos de 1960 também não sobreviveu além de uma acanhada e perplexa adolescência. Foi ab-rogado pela Lei n? 5.645 , de 10 de dezembro de 1970, que traça, desde logo, as diretrizes a que deverá obedecer o substitutivo. Vê-se, portanto, que as deficiências que tornaram inexeqüível o nôvo Plano, já estavam presentes no seu antepassado. Eram imperfeições do sistema em sua globalidade. Não sòmente da Administração de Pessoal, mas de muitos outros aspectos, paralelos e confluentes, do Serviço Público em geral. É notório, por exemplo, que - Plano de Classificação, devendo refletir uma realidade administrativa dinâmica e mutável, não poderia apresentar-se com uma roupagem rígida como a estranha vestimenta legal que the deram, dentro da qual jazia, apenas, matéria inerte: um plano de classificação estatelado, dependendo de interferência do Poder Legislativo para a mínima alteração. O legislador não compreendeu que os Planos de Classificação devem refletir o ritmo das transformações que ocorrem no conteúdo e no relacionamento das funções e que fora dessa premissa nada há o que justifique a sua elaboração. É claro, também, que êrro tão grosseiro de percepção, em matéria técnica, não poderia ser debitado às equipes especializadas que elaboraram o projeto. Continuava-se, por conseguinte, em 1960, sob a mesma conjuntura de 1954, com o Parlamento despreparado para entender que a finalidade dos planos de classificação de cargos é retratar a própria dinâmica dos cargos, e que, por conseguinte, um Plano de Classificação estático, ou de dinamismo lerdo, é uma contradição em têrmos. Mas também o Poder Executivo - cuique suum - vinha cometendo o êrro grave de não per- 
ceber a inviabilidade de classificar funções quando as relações entre as funções - e de certo modo a própria existência das funções - estavam dependendo de uma ação mais profunda, de envergadura maior: a reforma geral da maquinaria administrativa. Em tese, é claro que um plano de classificação de cargos, do mais caprichoso refinamento técnico, pode ser elaborado para refletir uma realidade defeituosa; mas ninguém pode lamentar, depois, o resultado infrutuoso. Na situação do Serviço Público Civil brasileiro, qualquer plano de classificação de cargos que fôsse estabelecido teria de retratar um universo de relações, de fato existentes, mas que, por não atenderem às efetivas necessidades do serviço, não deveriam existir. Quando, além de tudo, o Plano ficou sujeito a um regime inflexível de administração, que não comportava ajustamentos em ritmo adequado, era natural prever que se transformaria em bagaço no mesmo momento em que fôsse empreendida a reforma dos Serviços Públicos. A elaboração de um Plano de Classificação de Cargos é procedimento técnico complexo, minucioso, demorado e de elevado custo; só pode justificar-se quando é fora de dúvida a intenção de mantê-lo atualizado a qualquer preço. No nosso caso, um cometimento de tal envergadura não deveria ser nem mesmo objeto de cogitação enquanto não fôsse empreendida a Reforma Administrativa.

E tão correta esta assertiva que o problema volta à baila, agora, desta vez com tôda a gente convencida da necessidade cardeal de um Plano de Classificação de Cargos como corolário da Reforma Administrativa. Temos, por conseguinte, que, atacando o problema em 1952, de maneira categórica mas intempestiva; recobrando-o, em seguida, com o Plano malogrado de 1960; retoma-o o Govêrno hoje, transcorridos três lustros e pico, para reequacioná-lo. Voltamos, pràticamente, à estaca zero. Mas a perseverança é pelo menos comprovação de que a autoridade pública conhece a magnitude do assunto e não quer descurá-lo, apesar dos contratempos. Pelo contrário, quer absorver os resultados líquidos - isto é: descontados os desacertos - das frustradas experiências anteriores, em tudo que fôr compatível com uma focalização nova - quer dizer: corrigida - da problemática de classificação de cargos. Na verdade, os percalços da longa jornada que descrevemos ensinaram muita coisa útil; ensinaram principalmente isso: que as pistas escolhidas eram falsas e não podiam conduzir aos objetivos.

A Lei no 5.645, que estabelece a filosofia do nôvo Plano e abre para êle novos caminhos, está redigida em têrmos que parecem fazer tábua rasa de todos os estudos que a precederam. Até o estilo de redação adotado testemunha a preocupa- 
ção de inovar, de desobrigar-se do passado para escapar absolutamente dos seus erros. Reza a ementa, taxativamente: "Estabelece diretrizes para a classificação de cargos do Serviço Público Civil da União e das Autarquias Federais", e num dos últimos artigos aparece, lacônico, o epitáfio: "o atual Plano de Classificação de Cargos do Serviço Civil do Poder Executivo é considerado extinto".

Essas diretrizes, de alvissareiro realismo, parecem concebidas "to pave the way", para a elaboração do trabalho definitivo. Tudo parece indicar que os responsáveis pelo nôvo sistema de classificação vão encontrar a passagem desimpedida: alguns estorvos renitentes, finalmente eliminados, e as resistências mais contumazes, afinal aplacadas. Há o propósito deliberado de não permitir que os esforços empreendidos para dotar o Serviço Público de tão valioso instrumento de administração voltem a ser objeto de desfigurações como aquelas que comprometeram os ensaios anteriores.

Alguns aspectos da nova orientação precisam ser examinados e divulgados porque representam passos decisivos para a classificação de cargos e incidem, justamente, sôbre os pontos de estrangulamento que até hoje tornaram êsse cometimento inexeqüível.

De início vale ressaltar a sua maior conquista: o reconhecimento da competência do Poder Executivo para expedir, por decreto, o nôvo Plano. Isso significa desvincular um procedimento técnico, de caráter eminentemente especializado, das aventuras de uma discussão processada numa área leiga - o que sujeitaria o projeto ao risco maior de inúmeras e perigosas deformações. A experiência, com efeito, tem demonstrado, a tôda evidência, que os que não têm formação técnico-especializada não têm, igualmente, sensibilidade profissional para perceber que a peça sob exame constitui um complexo de partes entrosadas, que só comporta, por definição, alterações de conjunto.

Outra medida, de validez inquestionável, é a que engloba na sistemática geral de classificação os cargos do Poder Legislativo, do Poder Judiciário, do Tribunal de Contas da União, do Distrito Federal e dos Territórios, e determina a aplicação das diretrizes supracitadas aos planos específicos que tiverem de ser elaborados para cada uma das entidades referidas. Até o presente, o Poder Executivo, ainda que lograsse elaborar o plano mais perfeito, vê-lo-ia logo desfeito sob o impacto das confrontações desfavoráveis de remuneração. É fundamental se compreenda que, embora sejam numerosas as vantagens que 
um sistema de classificação de cargos proporciona, a isonomia salarial é o seu objeto direto. Assim, pois, e uma vez que os recursos orçamentários destinados à remuneração dos funcionários públicos dos três Podêres provêm da mesma fonte, não havendo interferência direta e conhecida do funcionário para o incremento da receita, não há meio de explicar, fora da prova produzida pela análise e avaliação dos cargos, por que percebem, em função aparentemente igual, salários diferentes. Vale recordar que o regime de remuneração com participação na arrecadação, a que já estiveram sujeitas algumas categorias funcionais do Executivo, embora sejam discutíveis os fundamentos dêsse sistema, nunca gerou maior descontentamento dos servidores não beneficiados. Isto se explica pela simples razão de que a interferência direta no incremento da receita era um pressuposto - e não importa, no caso, se verdadeiro.

Mas o legislador inteligente vai mais longe na compreensão das dificuldades que obstaculizam a elaboração dos planos de classificação no Serviço Civil brasileiro e preconiza o estabelecimento de escalas independentes de remuneração, para diferentes grupos de funções. Esta a diretriz técnica fundamental, sem a qual o nôvo Plano recairia na rigidez estéril dos anteriores, dominados por uma falsa concepção de equabilidade. A opinião técnica mais autorizada entende que a correlação entre os salários das funções só é consistente dentro de grupos de estreita homogeneidade.

Exemplificaremos com as funções de Analista de Laboratório e Analista de Sistemas. Poderiam ser os mesmos, porventura, os componentes da remuneração das duas funções assim entendidos os fatôres tomados em consideração para avaliação da função e fixação das faixas salariais respectivas. Se todavia sobrevém um aumento de remuneração, destinado a contrapesar o encarecimento geral do custo de vida, é lícito supor que ambas as funções terão majorações proporcionais. Mas, se ocorresse oscilação importante no mercado de mão- de-obra de uma dessas funções, poderia ser necessário ao Empregador rever o padrão salarial de uma delas, sem que por isso se impusesse alterar o da outra. Rompe-se, então, a relação existente? Sem dúvida, e assim deve ser. O fenômeno ocorre no campo real do mercado de trabalho. Importante, então, é que o sistema de classificação disponha de flexibilidade bastante para refletir a ocorrência.

Nos planos de classificação das Emprêsas modernas, a disponibilidade do mercado de trabalho é item obrigatório no 
rol dos fatôres de avaliação. Consideremos o exemplo da PETROBRÁS, que ilustra muito apropriadamente a questão; seja a função de Geólogo especializado em Petrologia, e imaginemos a profunda alteração do valor relativo dessa função se a PETROBRÁS deixasse de ser o único empregador nacional para êsse tipo de atividade. Como se vê, os Técnicos de Administração que assessoraram o legislador estavam, desta vez, atentos, também, para essa peculiaridade da mais moderna tecnologia de classificação.

Aqui, porém, outra peça importante do nôvo roteiro: a filosofia da descentralização, tônica da Reforma Administrativa de que o Plano de Classificação será o complemento necessário. Embora permanecendo com o órgão Central do Sistema de Pessoal a competência para expedir instruções e coordenar a execução, a elaboração do Plano de Classificação será efetivada independentemente, em cada Ministério ou Autarquia, por aquêles que possam ter, na exata medida, o conhecimento das funções a classificar. Está claro que a descentralização não elimina; torna, pelo contrário, mais necessária a presença atuante do DASP, que terá de prestar assistência técnica continuada aos órgãos de execução e zelar pela identidade dos procedimentos que forem adotados de Análise e Avaliação. O Órgão Central do Sistema de Pessoal deve estar atento, contudo, para não recair no absurdo das uniformidades espúrias que tanto contribuiram para tornar inautênticos os esquemas anteriores.

Há, portanto, todos os motivos para acreditar que o Serviço Público Civil ingressou na trilha certa, que finalmente proporcionará o advento de um Plano de Classificação de Cargos com as características comuns às boas peças do gênero: descentralização executiva, uniformidade de orientação, flexibilidade para o ajustamento à evolução tecnológica, congruência com os processos organizatórios e a reforma administrativa, e dignificação do exercício da função pública. A perspectiva é sobremaneira auspiciosa porque as diretrizes agora estabelecidas revelam a determinação de corrigir todos os erros de concepção que, por qualquer modo, contribuíram para retardar o andamento dos projetos anteriores, e põe em evidência o propósito de sobrestar as interferências, de tôda sorte, que os tornaram impraticáveis.

Há, todavia, um aspecto da Classificação de Cargos que não recebeu, nunca, a atenção que merece, quer no projeto abordado, de 1954, no Plano frustrado da Lei no $3.780 / 60$, ou mesmo nas Diretrizes, recém-prescritas. Referimo-nos à ava- 
liação dos cargos, usada a expressão em sua conotação específica, para significar a fase do processo geral de classificação que se ocupa em comparar funções, presumivelmente já classificadas, a fim de fixar-lhes o valor relativo. É possivel que - legislador atual não tenha considerado importante incluir no texto da lei qualquer referência explícita à questão. Mas a Exposição de Motivos que encaminha e justifica o anteprojeto elaborado pela Comissão da Reforma Administrativa do Pessoal Civil também não indica qualquer preocupação com o problema, que, sem embargo, nos parece da maior importância.

Receamos que em tôrno do assunto persistam algumas incorreções conceituais muito comuns, que, se não forem a tempo esclarecidas, poderão comprometer, mais uma vez, o empreendimento. Por isso, julgamos importante trazer essa matéria à colação para que seja objeto de exame por parte daqueles que houverem de assumir a responsabilidade direta de elaboração do nôvo Plano. É nossa opinião que os projetos anteriores se ressentiram do inadequado tratamento dispensado à avaliação das funções. Temos discutido êsse problema em várias oportunidades, no magistério, em artigos e livros. Para não nos tornarmos cansativos, faremos aqui, apenas uma sinopse, convidando os leitores porventura interessados a compulsar o livro "Avaliação de Funções", ${ }^{3}$ recentemente editado, onde o assunto é minuciosamente discutido e no qual figura alentada indicação bibliográfica.

De início devemos considerar a "classificação de cargos" como sendo apenas um procedimento destinado a permitir a clara e pronta visualização das unidades de trabalho existentes numa organização. São unidades de trabalho, segundo uma definição clássica, "o conjunto de deveres e responsabilidades cometiveis, em tempo integral, a um indivíduo". Assim sendo, o conjunto de deveres e responsabilidades concernentes, por exemplo, à execução de determinado serviço datilográfico pode compreender duas, três, dez ou mais funções se a carga de trabalho existente não fôr compatível com a capacidade normal de um indivíduo, na jornada de trabalho usual. Essa a confi-

* Nota da Redação - A "Avaliação dos Cargos Públicos Federais", tema relevante para qualquer administrador profissional, tem sido preocupação básica da atual Direção-Geral do DASP, que o vem estudando com um grupo de especialistas. O articulista desconhecia o fato. como é muito natural. Isso, porém, nẫo esgota o brilho e a fôrça das suas considerações.

3. Ennor de Almeida Carneiro - "Avaliação de Funções - Teoria e Prática" - Editôra "Ao Livro Técnico" S/A., Rio, GB, 1970. 
guração exemplar da unidade de trabalho a que convencionamos chamar cargo. 4 As diversas unidades de trabalho necessárias a que uma Organização possa realizar os seus objetivos diferem, uma das outras, sob numerosos aspectos, v.g.: qualificações necessárias ao desempenho satisfatório das tarefas (aí compreendida a instrução escolar, a experiência prática, a habilidade pessoal), condições sob as quais o trabalho se efetua (aí entendidas as condições de higiene e segurança dos locais de trabalho e os riscos eventuais), tipo de esfôrço que a execução das tarefas requer (abrangidos, nesse conceito, o esfôrço físico e o mental), natureza e grau das responsabilidades que afetam o executante (fator de grande complexidade que envolve responsabilidade por supervisão, responsabilidade pela segurança de terceiros, responsabilidade por verbas, equipamentos, informações confidenciais, contatos externos etc., etc. Êste apanhado, sumaríssimo, põe logo em evidência dois caracteres indefectíveis das funções: natureza e grau. Tôdas as características do trabalho desempenhado comportam observações sob êsses dois ângulos. As similitudes e as dessemelhanças se apresentam sob uma ou outra facêta. Dois cargos podem ser idênticos quanto à natureza do trabalho a realizar e diferentes quanto ao grau de dificuldade das tarefas afetas a cada um; e vice-versa, podemos deparar-nos com dois cargos de conteúdo completamente diverso (eletricista e topógrafo) e, sem embargo, ambos em nível equivalente de dificuldade, ou seja, ambos exigindo o mesmo nível de formação escolar ou o mesmo tempo de experiência prática. É possível, portanto, com base nessas considerações, fazer meticuloso levantamento de tôdas as características das funções, bem como confrontá-las (em natureza e grau) e, à luz dessa análise, constituir grupamentos mais ou menos homogêneos. A finalidade dêsses grupamentos é permitir que aos elementos constitutivos de cada conjunto possa ser dispensado um só tratamento, eliminandose a necessidade de considerar, isoladamente, cada função. É, portanto, claro que tôda a validade do sistema repousa sôbre os critérios de constituição dos grupos ou, em outras palavras, depende dos atributos de identificação que forem escolhidos. As coisas reunidas numa classe são idênticas relativamente a certos atributos. A classe é, nesse sentido, a unidade do sistema, visto que ela é individida (conceito que não deve ser confundido com indivisivel). Obtida, assim, uma classificação dos cargos, está extraordinàriamente facilitada a tarefa do adminis-

4. Ou função - (Não nos preocupam, nesta exposição, as sutilezas de nomenclatura). 
trador, no que diz respeito aos problemas de relações humanas no trabalho. Mas o grupamento das funções em entidades homogêneas ainda não fornece ao administrador os melhores recursos para que possa implantar um regime ideal de Administração de Pessoal. Falta-lhe, ainda, o exato conhecimento da importância relativa de cada um dêsses grupamentos (ou classes) com relação aos demais. Falta-lhe a informação essencial para elaboração dos esquemas de remuneração. Êsse ingrediente é a Avaliação de Funções. ${ }^{5}$ Êsse o instrumento, através do qual sopesamos e medimos os diversos cargos em seus componentes substanciais, para conhecer o valor relativo de cada um. Como está claro que as funções idênticas, por isso reunidas numa mesma classe, têm igual valor, é óbvio que a avaliação se processa depois de identificados e classificados os cargos. Ou seja: sopesam-se as classes de cargos para efeito de atribuir-lhes valôres relativos. Vejamos, ago$\mathrm{ra}$, onde reside o equívoco conceitual a que anteriormente nos referimos. Geralmente, no Serviço Público brasileiro, quando a etapa preliminar de classificação dos cargos se considera concluída, as "classes de cargos" apresentam-se escalonadas, constituindo unidades de ordem imediatamente superior, a que se convencionou chamar Série de Classes. Êsse escalonamento é uma hierarquia que, portanto, pressupöe um processo de avaliação - e com esta afirmativa dar-se-ia por assegurado que as funções foram avaliadas. Na realidade, entretanto, a ordenação das classes dentro de uma série pode garantir apenas um mínimo de coerência interna para êsse conjunto, significando o reconhecimento da existência de diferentes graus de complexidade entre as classes que compõem a Série. Mas a simples tripartição (é o que geralmente acontece) de uma atividade em diferentes escalões de dificuldade não significa que se tenha efetivamente medido o grau dessas diferenças. Não é jôgo de palavras: dividir a função de Agrimensor em Agrimensor de 1a, 2a e 3a; Agrimensor I, II e III ou AgrimensorEstagiário, Júnior e Sênior, é o reconhecimento de que as atividades dessa função se exercem em três diferentes níveis de dificuldade. Mas. .. in die busilles: qual a diferença entre êsses níveis? Do ponto de vista da retribuição, parece lógico que a composição tripartida da série conduza à fixação de três níveis de remuneração; mas ela não diz a razão da proporcionalidade a estabelecer. É verdade que os Planos de Glassificação elaborados no molde brasileiro usual compreendem também uma

5. Ou cargos (Teria razão Talleyrand? A palavra terá sido proporcionada ao homem "pour déguiser sa pensée"?). 
Escala Geral de níveis; p. ex.: de I a XVIII. Supõe-se que êsses níveis representem tôda a gradação possível entre as classes, ou tôda a gradação passível de justificar diferentes padrões de remuneração. Pretender-se-á, igualmente, que êsses níveis representam uma avaliação. Mas estamos caindo, assim, num círculo pernicioso, pois, uma vez constituída a Escala Geral, presume-se que as diversas Classes, das diversas Séries, serão enquadradas nos diversos Escalões. Eis, portanto, que ao Agrimensor-Estagiário pode ser designado o nivel III, ao Agrimensor Júnior o nível $V$ e ao Agrimensor-Sênior o nível XII. Qual foi, porém, o processo que permitiu fixar êsses espacejamentos? (De 3 para 5 e de 5 para 12). Estamos, mais uma vez, perante a Avaliação de Funções. ${ }^{6}$

Reduzindo o problema à sua expressão mais simples, teríamos de convir em que a "classificação de cargos" - toutcourt - não constitui o instrumento adequado para estabelecer a relação de importância entre as funções. Essa tarefa deve caber à Avaliação de Funções. Mas a expressão Classificação de Cargos, como ela é usada no âmbito do Serviço Público Brasileiro, deve ser compreendida, sempre, em sua acepção genérica, designando, simultâneamente, a "classificação", pròpriamente dita, das funções e sua "avaliação". A mesma coisa ocorre na sistemática de Administração de Pessoal do Serviço Civil norte-americano. A expressão norte-americana "position classification" abrange as duas categorias tecnológicas: a classificação e a avaliação das funções. Mas é preciso deixar bastante claro que nos E.U.A. o têrmo "classificação" tinha, ao lado da conotação genérica, uma conotação específica. No primeiro sentido, designava um método particular de avaliação, - "Classification Method", também conhecido pela denominação Sistema de Graus Predeterminados. No Brasil, traduzimos a denominação Classificação de Cargos, mas nem sempre nos demos conta do seu duplo significado. Nos primórdios do DASP, criado sob a inspiração de tratadistas norte-americanos, notadamente Willoughby, quando pela primeira vez a matéria era objeto de estudo sério, o modêlo escolhido foi o Relatório, de 1941, da Comissão de Classificação de Cargos e Planos de Pagamento da Civil Service Assembly of the United States and Canada, suculento tratado que, sob o título "Position - Classification in the Public Service", se transformou no livro-texto dos analistas de funções. Daí traduzimos a expressão "Classificação de Cargos". Mas é como adverte a paronomásia célebre:

6. Ou Cargos - "Des millieres d'hommes se firent tuer pour des paroles qu'ils n'ont jamais comprises et le plus souvent dépourvues du sens rationnel" (Gustave Le Bon, "Aphorismes du temps présent"). 
"traduttore, traditore". Deixamos passar até certo ponto despercebido o fato de que a expressão, quando usada para designar o processo de avaliação das funções, pretende significar, especificamente, que a dita avaliação será feita pelo método de distribuição das classes em graus sucessivos e predeterminados de importância. Mas é verdade também, e êste ponto é de excepcional relevância, que a Civil Service Comission, tendo desenvolvido numerosa tecnologia para análise e classificação das funções, não realizou trabalho de igual mérito, no tocante à avaliação de funções. E, assim, enquanto na indústria privada, sob o estímulo das lutas que se travavam para apropriada solução da questão salarial, aprimoravam-se os sistemas de apuração do valor relativo das funções, o Serviço Civil marcava passo, entregue a procedimentos demasiadamente subjetivos de avaliação. Com o tempo, a Civil Service Comission deu-se conta da sua desatualização e decidiu compensá-la pela descentralização dos processos de avaliação, permitindo às Secretarias de Estado que adotassem os seus próprios critérios de avaliação, com a exigência apenas de que o resultado final fôsse sempre expresso nos padrões usuais da Comissão. Era o reconhecimento de que novas formulações, oriundas da experiência das emprêsas, prometiam resultados mais exatos. Exemplo que vale sempre citar é o do Navy Department, que passou a avaliar funções pelo Sistema de Pontos, aderindo aos métodos quantitativos de avaliação. Essa a evolução que, ao nosso ver, o Serviço Público brasileiro está temeroso de acompanhar. Êsse, no nosso entender, o ponto crucial do problema. O Serviço Público brasileiro não elaborará esquemas válidos de remuneração enquanto não dispuser de um sistema igualmente eficaz para aferição do valor relativo das funções. E não disporá nunca de um sistema apropriado de medição enquanto preferir a sistemática superada do Serviço Público norte-americano, de teor demasiadamente subjetivo. O esfôrço e a diligência dos especialistas, desde o advento das técnicas de avaliação, com Merril Lott e Eugene Benge, em 1926, foi sempre dirigido no sentido de escapar à utilização das representações incongruentes da linguagem comum, substituindo-se pela simbologia - certamente também falivel, porém mais confiável das metodologias quantitativas. Atualmente, quase nenhuma emprêsa industrial de porte, em todo o mundo, foge à adoção dos métodos quantitativos de avaliação, que, -embora também manipulem valôres convencionais, podem fazê-lo em bases menos arbitrárias. (Com essa profissão de fé favorável aos métodos quantitativos de avaliação, talvez sejamos absolvidos da aspereza com que nos referimos, de início, ao excessivo zêlo 
"computadorizante".) O Serviço Público Federal, quando encara - assunto com a disposição de ânimo de que nos dá conta uma simples leitura da Lei $n^{\circ} 5.645$, não vai, certamente, descurar o importante problema da Avaliação de Funções, vista a questão sob o ângulo por que focalizamos. Há dois métodos disponíveis e bastante experimentados de avaliação por processos quantitativos, ambos de sucesso comprovado: o Sistema de Pontos e o Sistema de Comparação de Fatôres. A documentação disponível sôbre a utilização de qualquer dêsses métodos nas organizações privadas e no Serviço Público de outras nações é hoje abundante. É hora, portanto, de o Serviço Público brasileiro fazer uma opção. Essa decisão nos parece de importância indisfarçável, e estamos convencidos de que nela repousa todo o sucesso possível da terceira tentativa de elaboração de um Plano de Classificação de Cargos do Serviço Público Civil.

É hoje convicção mais ou menos generalizada entre os especialistas de Administração de Salários que a Avaliação de Funções, em suas versões técnicas mais aprimoradas, já atingiu padrões que a recomendam à utilização confiante de empregados e empregadores.

Convém assinalar, todavia, que a Avaliação de Funções não é placebo, não cura todos os males e, como tal, também não elimina a eventualidade de problemas oriundos de questões salariais. A avaliação pretende fixar o valor relativo das funções para, na relação daí decorrente, fundamentar os esquemas salariais; os resultados dependem, òbviamente, do acêrto ou desacêrto dos processos de medição adotados.

Para terminar, a clássica advertência: a Avaliação de Funções, peça fundamental de qualquer sistema de Administração de Pessoal digno dêsse nome, particularmente no campo da administração de salários, tem, não obstante, óbvias limitações. Mas outros instrumentos de trabalho do administrador, pacificamente aceitos, são também imperfeitos, e, não obstante, é impossível abrirmos mão dêles enquanto não encontrarmos melhor alternativa. A Avaliação de Funções, com uma história de meio século, continua sendo objeto de cotidiano aprimoramento. Daí, talvez, o segrêdo da sua vitalidade. Assim sendo, grande parte do que se afirma hoje, aqui, poderá perfeitamente ser refutado amanhã. E esperamos que assim seja porque, em comparação com os Estados Unidos e a Alemanha - para citar dois exemplos marcantes -, estamos ainda na primeira infância da avaliação de funções. A maturidade só será alcançada pelo debate construtivo e a contradição dialética. 


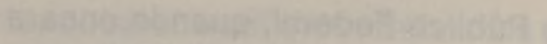

Wath

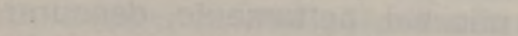

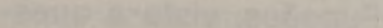

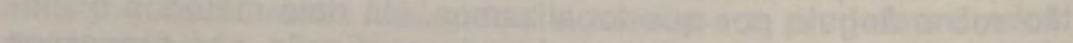

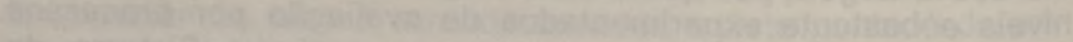

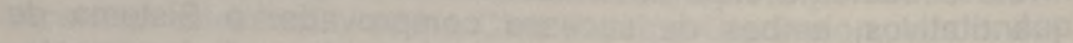

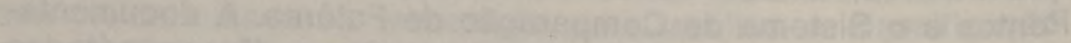

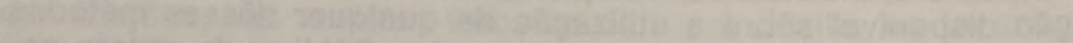

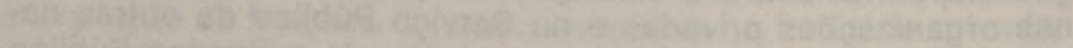

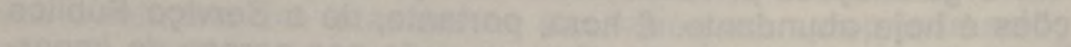

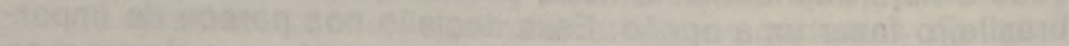

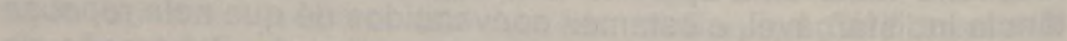

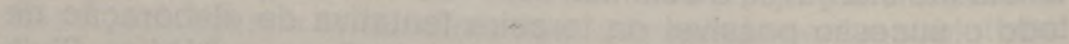

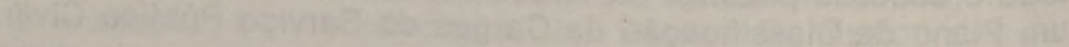

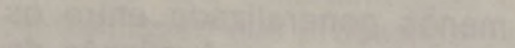

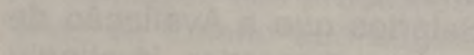

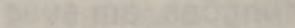

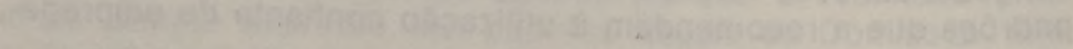

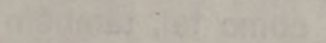

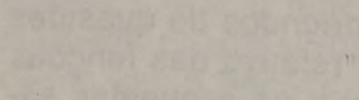

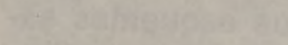

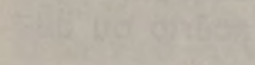

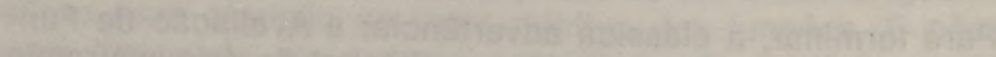

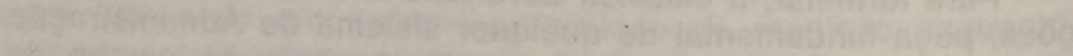

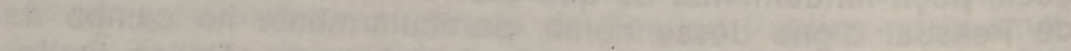

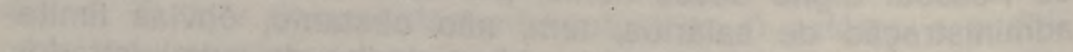

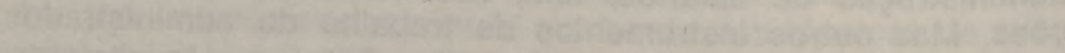

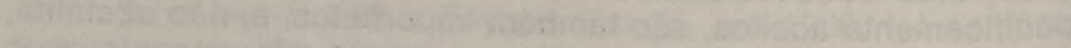

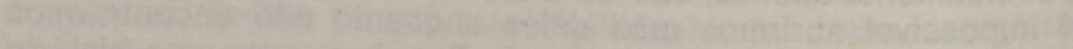

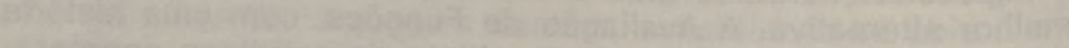

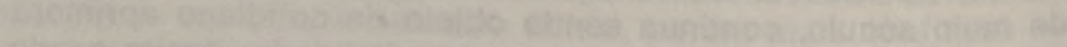

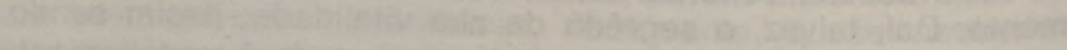

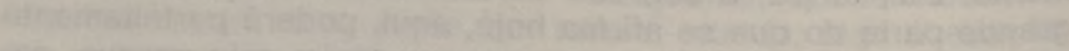

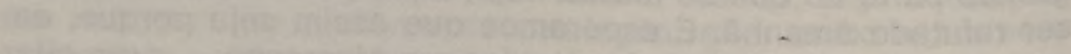

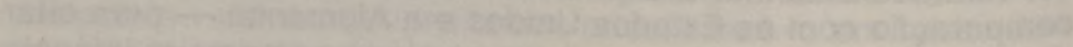

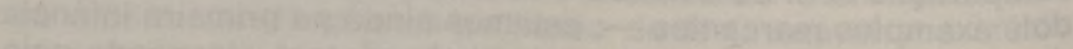
and

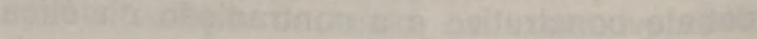

